Горян Э.В

\title{
ОБЕСПЕЧЕНИЕ ПРАВ ЖЕНЩИН, ЗАНЯТЫХ НА ПРОИЗВОДСТВЕ В СВОБОДНЫХ ЭКОНОМИЧЕСКИХ ЗОНАХ: МЕЖДУНАРОДНЫЕ СТАНДАРТЫ И ЗАРУБЕЖНЫЙ ОПЫТ
}

Аннотация. Объектом исследования выступают отношения по обеспечению трудовых прав женщиин в свободных экономических зонах. Автор исследует международно-правовой и национальный механизмы обеспечения международных трудовых стандартов. Внимание уделяется деятельности международных неправительственных организаций и многонациональных корпораций в данной сфере. Рассматриваются модели индивидуальной ответственности и совместной ответственности многонациональных компаний перед работниками на их производствах в развивающихся странах. Анализируется опыт США в оказании влияния на развиваюшиеся страны в сфере обеспечения международных трудовых стандартов. С иелью получения наиболее достоверных научных результатов был использован ряд общенаучных (системно-структурный, формально-логический и герменевтический методы) и специальных юридических методов познания (сравнительно-правовой и формально-юридический методы). Использование этих методов имело комплексный характер. Последние тендениии свидетельствуют о все более активном участии многоначиональных корпораций к обеспечению прав трудящихся на их предприятиях, которые расположены в большинстве своем в свободных экономических зонах. Трудности создают непосредственно государства, на территории которых находятся предприятия - коррупция, несовершенные правовые и институциональные механизмы, отсутствие политической воли к разрешению проблем стоят на пути ратификации и дальнейшей имплементации международных стандартов труда. Наиболее действенным средством принуждения государства к выполнению международных обязательств в данной сфере являются торговые соглашения с развитыми государствами, содержащие спечиальные оговорки относительно взаимосвязи соблюдения международных трудовых стандартов и предоставления торговых преференций.

Ключевые слова: Права человека, международные трудовые стандарты, свободная экономическая зона, многонациональная корпорация, неправительственная организачия, торговые соглашения, профсоюз, начиональный механизм, международный механизм, достойный труд.

Abstract: The object of this research is the relations pertaining to protection of the women's labor rights in the free economic zones. The author explores the international legal and national mechanisms of ensuring the international labor standards. Attention is given to the work of international nongovernmental organizations and multinational corporations in this field. The author examines the models of individual responsibility, as well as joint responsibility of the multinational corporation before the employees in developing countries. The experience of US impact upon the developing countries regarding the protection of international labor standards is being analyzed. The latest trends testify to the more active 
participation of multinational corporations in protection of the rights of employees at the work places mostly located throughout the free economic zones. The difficulties are created directly by the countries, on the territories of which the factories are located-corruption, flawed legal and institutional mechanisms, lack of political will towards resolution of the issues hinder the ratification and further implementation of the international labor standards. Trade agreements with the developed countries, which contain special clauses regarding the interdependence between compliance with the international labor standards and provision of trade preferences, serve as the most efficient means of compulsion of the states to fulfill their international obligations.

Keywords: Trade treaty, nongovernmental organization, multinational corporation, free economic zones, international labour standards, human rights, Trade Union, national mechanism, international mechanism, decent joob.

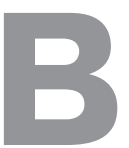

соответствии с Международной конвенцией по упрощению и гармонизации таможенных процедур под свободной экономической зоной понимается часть государственной территории, на которой помещенные там товары рассматриваются с точки зрения взимания импортных таможенных пошлин и налогов как находящиеся вне таможенной территории и не подлежащие обычному таможенному контролю [1]. В юридической литературе понятие СЭЗ рассматривается более широко [2], поскольку государства устанавливают особый правовой режим для такой части своей территории (особые благоприятные условия для деятельности предприятий), включающий налоговые, валютно-финансовые, таможенные, административные, гражданско-правовые и иные льготы и гарантии. С течением времени СЭЗ эволюционировали от простых форм деятельности (торговый тип СЭЗ) к сложным (производство массовой и высокотехнологичной продукции, предоставление услуг), от дешевых вариантов к более капиталоемким и дорогим. В зависимости от реализуемых целей государство идет на создание в стране различных СЭЗ, которых в современной мировой практике существует более 25 разновидностей [2].

Одной из особенностей специальных экономических зон (далее - СЭЗ) является возможность установления специального режима труда для лиц, занятых в производстве. Как правило, государства, руководствуясь благой целью привлечения инвестиций, идут на смягчение стандартов в сфере охраны труда, чем привлекают многонациональные (транснациональные) корпорации (далее - МНК) для размещения своих производств на предприятиях, где отсутствует профсоюзное представительство работников [3, с. 128)]. Кроме свободы ассоциаций, в указанных государствах наблюдаются такие нарушения трудовых прав, как дискриминация по признакам пола и возраста, нарушения прав женщин-матерей, детский труд, принудительный труд, нарушение условий труда и проч. [4].

Вопросы обеспечения прав трудящихся в СЭЗ рассматривались в контексте разработки правил социальной политики МНК на универсальном уровне. Однако усилия государств и международных организаций (МОТ, ОЭСР) не привели к ожидаемым результатам [3, с. 128].

Международные организации издают разной степени рекомендации, касающиеся защиты труда в СЭЗ. Например, ВТО в Правилах и практике применения экспортной политики не делает отдельный акцент на правах трудящихся [5]. В 1996 г., на Сингапурской Министерской конферен- 
ции ВТО члены организации подтвердили свою приверженность соблюдению международно-признанных основных трудовых стандартов и назвали МОТ «компетентной организацией» для разработки таких стандартов. В Сингапурской декларации министров члены ВТО: (1) подтверждают свою поддержку работе МОТ по продвижению «международно-признанных трудовых стандартов»: праву на организацию и ведение коллективных переговоров, защиту от принудительного труда, запрет детского труда, включая «худшие формы детской эксплуатации», приемлемые условия труда, включающие минимальную оплату, продолжительность работы, безопасность труда и здоровья; (2) верят, что экономический рост, развитие и дальнейшая либерализация торговли будет способствовать продвижению этих стандартов; (3) отказываются от использования трудовых стандартов для протекционистских целей; (4) отмечают, что ВТО и Секретариат МОТ продолжат уже сложившееся сотрудничество [6].

МОТ подготовила ряд докладов, посвященных условиям труда в зонах обработки экспорта. Ни один из них, однако, не содержит актуальных данных о государствах, где законы допускают различные трудовые стандарты в зонах свободной торговли. В докладе 2008 г. МОТ исследовала практику деятельности транснациональных корпораций в странах-участницах соглашений о свободной торговле. Было указано, что такие компании неравномерно реализуют свои трудовые стандарты. Хотя условия труда в СЭЗ иногда лучше, чем в целом по стране, плохие условия труда с точки зрения сверхурочной работы, обеспечения безопасности труда и здоровья, заработной платы и свободы ассоциации остаются проблемой всех зон [7].

Подавляющее большинство работников СЭ3 (70-90\%) представлено молодыми ма- лообеспеченными женщинами, зачастую внутренними мигрантами из сельских районов. Для большинства из них работа на предприятиях СЭЗ (текстильная промышленность и электроника) является первым опытом на рынке труда, поэтому они не осведомлены о своих правах, а тем более о профсоюзах. Такие женщины находятся в самом начале глобальной цепочки создания добавочной стоимости и сталкиваются со множеством проблем: опасные условия труда, недостаточная охрана материнства, сексуальные домогательства, отсутствие права голоса в профсоюзных органах. Работодатели предпочитают нанимать молодых женщин за их быстроту, терпение и ловкость, а также высокую выносливость в монотонных производственных операциях, так необходимые для выполнения трудоемких и монотонных операций. Поэтому они представлены в основном в низкоквалифицированном сегменте, а если заняты в наукоемком производстве, то их заработная плата гораздо меньше, чем у мужчин на той же должности. У них, как правило, нет детей, они скорее всего не будут обращаться или вступать в профсоюз, а следовательно - будут создавать меньше проблем работодателю. Что касается профсоюзов, то женщины-рабочие зачастую не представляют себе их функции, а в случае членства их интересы недостаточно представлены. Вышеперечисленные факторы делают женщин самыми эксплуатируемыми среди рабочих СЭЗ [8].

Как было сказано выше, сверхурочная работа является распространенным явлением во всех СЭВ мира. В результате женщины-рабочие, особенно молодого возраста, подвергаются домогательствам во время работы, во время возвращения с работы в вечерние часы или в другое время. Эта ситуация усугубляется плохим транспортным сообщением, что заставляет женщин 
проходить пешком большие расстояния до работы, зачастую покидая дом ранним утром и возвращаясь домой после захода солнца. Из-за характера выполняемой работы, которая неблагоприятно отображается на их здоровье, женщины вынуждены увольняться, поэтому существует высокая текучесть рабочей силы. Недостаток эффективной социальной защиты приводит к тому, что женщины остаются экономически зависимы после увольнения, а отсутствие профессиональной переподготовки заставляет их искать менее выгодные рабочие места или лишает их возможности самостоятельной занятости.

Фактором, ухудшающим положение женщин, занятых на производстве в ОЭЗ, является наличие детей, поскольку во многих государствах законодательство запрещает детям находиться на территории СЭВ. Услуги яслей и дошкольных учреждений по месту жительства, как правило, недоступны или недостаточны, а расходы непомерно велики для работающих женщин. Это может быть причиной опозданий на работу, прогулов и высокой текучести рабочей силы, столь частых среди женщин в СЭВ.

Исследователи отмечают еще такое нарушение прав женщин, как отсутствие доступа к еде хорошего качестве в достаточном количестве. В результате они подвержены расстройствам здоровья и недоеданию. В СЭВ зачастую отсутствуют службы здравоохранения, а если они и есть, то количество предоставляемых услуг ограничено, оказание женщинам специальных видов медицинской помощи невозможно в виду отсутствия соответствующего оборудования [8]. Несмотря большое количество преступлений на сексуальной почве, в СЭВ отсутствуют независимые и конфиденциальные службы, куда женщины могут обратиться с жалобами и за разными видами помощи, а администрация СЭВ не предпринимает мер по наказанию руководителей, которые домогаются подчиненных.

Как было отмечено выше, подавляющее большинство работников на производствах представлено молодыми женщинами. Исследователи отмечают заинтересованность работодателя в сотрудниках младше 23 лет, поскольку они более послушны и ловки. Как правило, лицам старше 23 лет труднее получить работу и их увольняют по причине возраста, а также если они собираются выходить замуж или рожать ребенка, или активно участвуют в профсоюзе. В результате, например, в Гватемале $45 \%$ женщин-трудящихся составляют матери-одиночки, а в Никарагуа 66\% женщин содержат более 3 членов семьи. Поскольку многие рабочие представлены внутренними мигрантами из отдаленных районов, они вынуждены жить рядом с СЭВ в переполненных общежитиях в недопустимых санитарных условиях. Женщины испытывают трудности с совмещением домашних обязанностей и работы, для многих недоступны детские ясли по причине их отсутствия или высокой стоимости услуг. В некоторых государствах, например, Шри-Ланке, мигранты-трудящиеся имеют более низкий социальный статус, позволяющий их эксплуатацию и приводящий к дальнейшей маргинализации. Они лишены права организовывать профсоюзы, подвергаются жестокому обращению и физической расправе со стороны работодателей в случае попытки такой организации [8].

Международной организацией труда были разработаны и утверждены соответствующих механизмы обеспечения прав женщин-трудящихся, многие развивающиеся страны их ратифицировали, однако де-факто права женщин продолжают нарушаться. Это можно объяснить как несовершенством национальных механизмов, так и нежеланием государств терять инвесторов, размещающих предприятия на их террито- 
рии и устанавливающих частные стандарты труда, а также фактическим отсутствием механизмов контроля за их деятельностью.

Однако последнее время существует тенденция продвижения института корпоративной ответственности всей цепочки производства. В мае 2011 г. Организация экономического сотрудничества и развития (ОЭСР) издала обновленные Руководящие принципы ОЭСР для многонациональных предприятий рекомендации по ответственному ведению бизнеса в контексте глобализации (далее - Принципы). Согласно этому документу, МНК, осуществляющие деятельность в государствах-членах ОЭСР, обязаны осуществлять «должную осмотрительность» для соблюдения ими и их поставщиками согласованных стандартов «надлежащего корпоративного поведения» (good corporate behavior), в частности: 1) уважать права человека, то есть они должны избегать ущемления прав человека и других лиц и должны рассматривать негативные воздействия прав человека на лица, с которыми они ведут деятельность; 2) в рамках своей деятельности не вызывать или способствовать негативному воздействию на права человека и предотвращать такое воздействие, когда оно происходит; 3) искать пути для предотвращения или смягчения негативного воздействия на права человека, которое возникает непосредственно в результате их хозяйственной деятельности, продукции или услуг, даже если они не участвуют в этих последствиях; 4) проводить политику приверженности к уважению прав человека; 5) проводить комплексную проверку прав человека в соответствии с их объемом, характером и контекстом деятельности и тяжести рисков негативного воздействия прав человека; 6) обеспечить или сотрудничать посредством законных процессов в восстановлении негативного воздействия на права человека там, где они определяют, что они привели или способствовали этим воздействиям [9].

Раздел IV Принципов, посвященный правам человека, в значительной степени опирается на Руководящие принципы предпринимательской деятельности в аспекте прав человека, одобренные Советом по правам человека ООН [10]. Однако на практике складывается два разных подхода к социально ответственной цепочке поставок (socially responsible global supply chain) [11]. Всемирный экономический форум (ВЭФ) в последнее время выступает за подход «совместной ответственности», заключающийся в координации действий МНК, местных органов власти и международных организаций. В противовес ему, корпорация Nike выбрала стратегию, которая подчеркивает индивидуальную ответственность компании в странах и предприятиях, где он может обеспечивать, контролировать международные стандарты труда и обеспечения прав человека. В юридической науке был поставлен вопрос: насколько решение Nike ограничить свою ответственность странами и предприятиями является разумной и приемлемой политикой? [11, p. 312]. Для ответа на этот вопрос исследователи предлагают обратиться к ситуации, сложившейся в 1993 г. с компанией Levi Strauss \& Co., производителем фирменной одежды. Руководство компании решало, стоит ли размещать производственные мощности в Китае с учетом существующих там проблем обеспечения прав человека. Они использовали разработанный компанией «подход принципиальной аргументации» (principled reasoning approach), который основывался на этических ценностях компании и недавно принятых универсальных принципах сорсинга (сорсинг - оптимизация процессов закупочной деятельности компании, направленные на получения экономии и повышения рентабельности). Подобный 
«подход принципиальной аргументации» может использоваться другими компаниями как способ принятия решения в случае, если они решат принять модель совместной ответственности [12].

Однако в литературе высказывается мнение, что решение Nike ограничить свою ответственность собственными предприятиями не решает реальную проблему, требующую от МНК обязательств по осуществлению коллективных действий для защиты трудовых прав работников предприятий [13]. В качестве примера приводится ситуация в Бангладеш, где расположенные крупнейшие текстильные предприятия МНК.

Бангладеш ратифицировал семь из восьми фундаментальных конвенций МOT, посвященных основополагающим правам и принципам в сфере труда: Конвенцию №87 относительно свободы ассоциаций и защиты права на организацию 1948 г.; Конвенцию №98 относительно применения принципов права на организацию и на заключение коллективных договоров 1949 г.; Конвенцию №100 о равном вознаграждении мужчин и женщин за труд равной ценности 1951 г.; Конвенцию №111 о дискриминации в области труда и занятий 1958 г.; Конвенцию №29 о принудительном или обязательном труде 1930 г.; Конвенцию №105 об упразднении принудительного труда 1957 г.; Конвенцию №182 о запрещении и немедленных мерах по искоренению наихудших форм детского труда 1999 г. Исключение составляет Конвенция №138 о минимальном возрасте приема на работу 1973 г.

Как указывается в Декларации МОТ об основополагающих принципах и правах в сфере труда 1998 г., выполнение этих принципов и прав обязательно вне зависимости от факта ратификации, а лишь в силу присоединения государства к Уставу MOT. Поскольку не все эти принципы и права четко и однозначно сформулирова- ны в Уставе МОТ и прилагающейся к нему Декларации относительно целей и задач Международной организации труда 1944 г. (Филадельфийской декларации), исследователи делают вывод, что МОТ относит данные конвенции к «императивным нормам общего международного права (ius cogens)», которые, согласно Венской конвенции о праве международных договоров 1969 г., имеют преимущество перед обычными международными договорами [14].

Из 4 приоритетных конвенций МOT, выделенных в качестве таковых административным советом МOT, Бангладеш ратифицировал всего две: Конвенцию №81 об инспекции труда в промышленности и торговле 1947 г. и Конвенцию №144 о трехсторонних консультациях для содействия применению международных трудовых норм 1976 г. Эти конвенции вместе с Конвенцией №122 о политике в области занятости 1964 г. и Конвенцией №129 об инспекции труда в сельском хозяйстве 1969 г. выделены в особую группу с целью содействия их ратификации максимально большим количеством государств - участников МOT. С 2004 года сведения об их ратификации государствами - членами МОТ включаются в Информационный документ о ратификациях и деятельности, связанной с нормами, предоставляемый ежегодно Международной конференции труда.

В отношении и фундаментальных, и приоритетных конвенций каждое государство - член MOT, ратифицировавшее соответствующую конвенцию, обязано предоставлять отчеты о выполнении содержащихся в них положений Комитету экспертов MOT по применению конвенций и рекомендаций, который на основе этих отчетов составляет доклад об их соблюдении.

Для улучшения условий труда работников в Бангладеш необходимо, в частности, согласовать стандарты систем противо- 
пожарной безопасности, электроснабжения, промышленной безопасности и т.д. Согласованные стандарты должны быть закреплены в национальном законодательстве Бангладеш. Утверждение нового Стандарта ISO 45001 для систем управления, касающихся профессиональной безопасности и здоровья предоставляет МНК еще одну возможность создания «надлежащей правовой процедуры» для субподрядчиков, предусматривающую расторжении контракта в случае нарушения ими указанных стандартов [15]. Под давлением МНК и международных организаций власти Бангладеш пытаются исправить сложившуюся ситуацию. Так, в 2013 г. был принят Закон о труде, включивший положения о безопасности на рабочих местах. Правительство также разработало Трехсторонний план действий по пожарной и промышленной безопасности, касающийся текстильной промышленности, но многие пункты плана так и не были выполнены. Кроме того, правительство пыталось улучшить действующие стандарты безопасности предприятий-субподрядчиков, требуя от них вступления в одну из двух национальных ассоциаций производителей одежды страны; но ассоциации отказали в членстве субподрядных предприятиям из-за опасений по поводу несоответствия стандартов заявленному уровню обеспечения. Одним из факторов, замедляющих улучшение стандартов труда до международного уровня в Бангладеш, является коррупция, поэтому исследователи настаивают на необходимости привлечения сторонних аудиторов, таких как FLA (The Fair Labor Association, Ассоциация справедливого труда - неправительственная организация, объединяющая университеты, общественные организации и предпринимателей, оказывающая содействие соблюдению международных и национальных законов о труде [16] для продвижения стандартов пожарной и промышленной безопасности [11, p. 313].

Вышеприведенный пример иллюстрирует развитие нового механизма обеспечения прав трудящихся - ключевую роль играют непосредственно МНК, реагирующие на мировую тенденцию социально осознанного потребления: потребители из развитых стран делают выбор в пользу продукции, произведенной без нарушения прав человека и без причинения ущерба окружающей среде. Когда речь идет об использовании международных механизмов, в частности МOT, ситуация приобретает спорный характер. В Декларации о социальной справедливости в целях справедливой глобализации 2008 г. достойный труд был определен в качестве программы действий МОТ [17]. Как отмечает Н.Л. Лютов, противоречия между экономически развитыми и развивающимися странами, связанные с противоположной мотивацией, вызвали существенные трудности при принятии новых и ратификации ранее принятых конвенций МОТ. Проблема принятия норм международного трудового права под влиянием протекционистских соображений осталась актуальной и до настоящего времени. Развивающиеся страны нередко обвиняют экономически развитые государства в установлении с помощью международных трудовых стандартов барьеров в международной торговле [3, с. 129]. На наш взгляд, такие обвинения делаются с целью избежать ответственности за нарушение прав трудящихся и свидетельствует о нежелании решать сложившуюся проблему. К слову, США оказывает влияние на обеспечение прав трудящихся, в том числе и занятых на производстве в СЭЗ, путем издания законов о торговых преференциях и заключения соглашений о свободной торговле. В законах о торговых преференциях указываются, помимо всего прочего, условия предоставления странам постоянного права 
на торговые льготы, содержащие требования к обеспечению «международно-признанных прав трудящихся» (internationally recognized worker rights). Как указано в Федеральном акте о торговле 1974 г., к международно-признанным правам трудящихся относятся: (a) свобода ассоциаций; (b) право на организацию и ведение коллективных переговоров; (c) запрет на использование любой формы принудительного или обязательного труда; (d) запрет детского труда, включая «худшие формы детской эксплуатации»; (е) приемлемые условия труда, включающие минимальную оплату, продолжительность работы, безопасность труда и здоровья [18].

Почти все торговые соглашения США о свободной торговле включают аналогичные нормы о защите прав трудящихся. Во всех договорах, за исключением Торгового соглашения между США и Израилем, Торгового соглашения США и Канады о свободной торговле и Североамериканского соглашения о свободной торговле (North American Free Trade Agreement, NAFTA), содержатся положения о недопущении Сторон «отменять или исключать» нормы трудового права для привлечения торговых или инвестиционных партнеров третьей Стороны. Такие положения были практически дословно включены в 12 торговых соглашений США, а в четырех соглашениях (Перу, Колумбия, Панама и Южная Корея) подобный запрет вытекает из смысла процедур решения споров.

Однако «серую» зону применения вышеуказанных положений из соглашений о свободной торговле и программ торговых преференций составляют зоны свободной торговли, по крайне мере в некоторых соглашениях о свободной торговле. В то время, как США отменила торговые преференции для некоторых стран из-за нарушений прав трудящихся (например, Мьянмы в 2002-2012 гг.), применимость положений об обеспечении прав трудящихся из со- глашений о свободной торговле в других странах еще не подвергалась рассмотрению с использованием процедуры решения споров. В большинстве соглашений о свободной торговле под термином «территория» понимается также и «исключительная экономическая зона» (определение которой в соглашении не дается). Однако в положениях, касающихся обязательств в сфере труда, термин «территория» обычно используется в нормах, которые обычно не подлежат исполнению на основе положений процедуры разрешения споров. В более поздних соглашениях с Перу, Колумбия, Панама и Южная Корея термин «территория» появляется в разделе о трудовой кооперации и развитии торгового потенциала.

Как уже было сказано ранее, в зависимости от законодательства конкретного государства обеспечение прав трудящихся в СЭЗ может отличаться от общепринятого в стране. Так, один из торговых партнеров США - Иордания допустила смягчение стандартов труда в СЭЗ. Факт такого смягчения был обнаружен в 2006 году, когда Национальный комитет по труду (the National Labor Committee, c 2011 г. - The Institute for Global Labour and Human Rights) опубликовал доклад, иллюстрирующий проблемные условия труда в зонах свободной торговли Иордании - квалифицированных промышленных зонах [19]. Вопрос был обсужден на переговорах трудовых представителей США и Иордании, и Иордания предприняла ряд шагов для решения проблем. Так как этот вопрос решался неофициально, он не создал прецедента установления международно-признанных стандартов труда во всех зонах свободной торговли государств, с которыми США имеют соглашения о свободной торговле. В проекте Соглашения о Транстихоокеанском партнерстве, представленном США, содержатся положения, обязывающие страны-участницы принять 
и придерживаться принципов МOT, а также применять национальное трудовое законодательство в ЗСТ и зонах обработки экспорта (export processing zones) [20].

Обеспечение международных трудовых стандартов в свободных экономических зонах осуществляется на основе международного механизма, включающего не только MOT, но и неправительственные организации. Последние тенденции свидетельствуют о все более активном участии многонациональных корпораций к обеспечению прав трудящихся на их предприятиях, которые расположены в большинстве своем в СЭЗ. Корпорации используют один из разработанных подходов - индивидуальной ответственности или совместной ответствен- ности для достижения указанной цели. Трудности создают непосредственно государства, на территории которых находятся предприятия - коррупция, несовершенные правовые и институциональные механизмы, отсутствие политической воли к разрешению проблем стоят на пути ратификации и дальнейшей имплементации международных стандартов труда. Наиболее действенным средством принуждения государства к выполнению международных обязательств в данной сфере являются торговые соглашения с развитыми государствами, содержащие специальные оговорки относительно взаимосвязи соблюдения международных трудовых стандартов и предоставления торговых преференций.

\section{Библиография:}

1. Международная конвенция об упрощении и гармонизации таможенных процедур (совершено в Киото 18.05.1973) (в ред. Протокола от 26.06.1999) [Электронный ресурс] // СПС «КонсультантПлюс». - Режим доступа: http://www.consultant.ru/cons/cgi/online.cgi?req=do $\mathrm{c} \&$ base $=\mathrm{LAW} \& \mathrm{n}=106124 \& \mathrm{fld}=134 \& \mathrm{dst}=100788,0 \& \mathrm{rnd}=0.8256902086784232$ (дата обращения $-07.08 .2016)$

2. Павлов П.В. Особые экономические зоны как механизм эффективного развития международной инвестиционной и инновационной деятельности / П.В. Павлов // NB: Международные отношения. - 2013. - № 1. - C.51-144. DOI: 10.7256/2306-4226.2013.1.638. URL: http://e-notabene.ru/wi/ article_638.html (дата обращения - 07.08.2016)

3. Лютов Н.Л. Международные трудовые стандарты и международная торговля в условиях глобализации: проблемы взаимодействия (в свете вступления России в ВТО / Н.Л. Лютов // Российский юридический журнал. - 2013. - №6(93). - С. 127-134

4. Trade Union manual on export processing zones (2014) // International Labour Organisation: официальный сайт [Электронный ресурс]. - Режим доступа: http://www.ilo.org/wcmsp5/groups/public/--ed_dialogue/---actrav/documents/publication/wcms_324632.pdf (дата обращения - 07.08.2016)

5. WTO Rules and Good Practice on Export Policy (March, 1997) // World Trade Organisation: официальный сайт. [Электронный ресурс]. - Режим доступа: https://www.wto.org/english/res e/reser_e/ ptpr9701.pdf (дата обращения - 07.08.2016)

6. Singapore WTO Ministerial 1996: Ministerial Declaration WT/MIN(96)/DEC // World Trade Organisation: официальный сайт. [Электронный ресурс]. - Режим доступа: https://www.wto.org/ english/thewto_e/minist_e/min96_e/wtodec_e.htm (дата обращения - 07.08.2016)

7. Milberg W., Amengual M. Economic Development and Working Conditions in Export Processing Zones: A Survey of Trends / W. Milberg, M. Amengual. - Geneva, 2008 // International Labour Organisation: официальный сайт. [Электронный ресурс]. - Режим доступа: http://ilo.org/public/ french/dialogue/download/wp3englishfinal.pdf (дата обращения - 07.08.2016), p. 62

8. Trade Union manual on export processing zones (2014) // International Labour Organisation: официальный сайт [Электронный ресурс]. - Режим доступа: http://www.ilo.org/wcmsp5/groups/public/--ed_dialogue/---actrav/documents/publication/wcms_324632.pdf (дата обращения - 07.08.2016) 
9. Руководящие принципы ОЭСР для многонациональных предприятий рекомендации по ответственному ведению бизнеса в контексте глобализации (2011) // The Organisation for Economic Co-operation and Development: официальный сайт [Электронный ресурс]. - Режим доступа: http:// mneguidelines.oecd.org/text/MNEGuidelinesRussian.pdf (дата обращения - 07.08.2016)

10. Guiding Principles on Business and Human Rights (2011) // The Office of the United Nations High Commissioner for Human Rights: официальный сайт [Электронный ресурс]. - Режим доступа: http://www.ohchr.org/Documents/Publications/GuidingPrinciplesBusinessHR_EN (дата обращения $-07.08 .2016)$

11. Hemphill T.A., White G.O. III. The World Economic Forum and Nike: Emerging 'Shared Responsibility' and Institutional Control Models for Achieving a Socially Responsible Global Supply Chain? / T.A. Hemphill, G.O. White III // Business and Human Rights Journal. - 2016. - №1. - Pp. 307-313. doi:10.1017/bhj.2016.3

12. Paine L.S., Katz J.P. Levi Strauss \& Co.: Global Sourcing (A) / L.S. Paine, J.P. Katz // Harvard University Graduate School of Business Administration Case \#9-395-f, November 1994 (revised February 1997).

- Boston: Harvard Business School Press, pp.127-128.

13. Posner M.S. Disney and Other Big Brands Need to Address the Real Challenges to Outsourcing / M.S. Posner // The New York Times, (2 May 2013). [Электронный pecypc]. - Режим доступа: http://www. nytimes.com/roomfordebate/2013/05/02/when-does-corporate-responsibilitymean-abandoning-ship/ disney-and-other-big-brands-need-to-address-the-real-challenges-to-outsourcing (дата обращения $-07.08 .2016)$

14. Лютов Н.Л. Перспективы ратификации Россией конвенций МОТ / Н.Л. Лютов // Трудовое право. - 2010. - №2(120). - С. 89-96. - С. 90

15. Cooper S. Improving Worker Safety in Global Supply Chains: The Case for a Global Safety \& Health Management System / S. Cooper // Professional Safety. - 2014. - October. - Pp. 29-33

16. The Fair Labor Association: официальный сайт [Электронный ресурс]. - Режим доступа: http:// www.fairlabor.org/ (дата обращения - 07.08.2016)

17. Декларация МОТ о социальной справедливости в целях справедливой глобализации 2008 г. [Электронный pecypc]. - Режим доступа: http://www.ilo.org/wcmsp5/groups/public/---europe/--ro-geneva/---sro-moscow/documents/genericdocument/wcms_100193.pdf (дата обращения $-07.08 .2016)$

18. U.S. Code Chapter 12 - Trade Act of 1974 // Legal Information Institute: официальный сайт. [Электронный ресурс]. - Режим доступа: https://www.law.cornell.edu/uscode/text/19/chapter-12 (дата обращения - 07.08.2016)

19. National Labor Committee, U.S. - Jordan Free Trade Agreement Descends into Human Trafficking and Involuntary Servitude, May, 2006, 161 р. [Электронный ресурс]. - Режим доступа: http:// www.globallabourrights.org/reports/u-s-jordan-free-trade-agreement-descends-into-human-trafficking-and-involuntary-servitude (дата обращения - 07.08.2016)

20. USTR Tables TPP Labor Proposal That Goes Beyond May 10 Template // World Trade Online: официальный сайт. [Электронный ресурс]. - Режим доступа: http://insidetrade.com/inside-us-trade/ ustr-tables-tpp-labor-proposal-goes-beyond-may-10-template (дата обращения - 07.08.2016)

\section{References (transliterated):}

1. Pavlov P.V. Osobye ekonomicheskie zony kak mekhanizm effektivnogo razvitiya mezhdunarodnoi investitsionnoi i innovatsionnoi deyatel'nosti / P.V. Pavlov // NB: Mezhdunarodnye otnosheniya. - 2013. - № 1. - S.51-144. DOI: 10.7256/2306-4226.2013.1.638. URL: http://e-notabene.ru/wi/article_638.html (data obrashcheniya - 07.08.2016)

2. Lyutov N.L. Mezhdunarodnye trudovye standarty i mezhdunarodnaya torgovlya v usloviyakh globalizatsii: problemy vzaimodeistviya (v svete vstupleniya Rossii v VTO / N.L. Lyutov // Rossiiskii yuridicheskii zhurnal. - 2013. - №6(93). - S. 127-134 
DOI: $10.7256 / 2226-6305.2016 .4 .20009$

При цитировании этой статьи сноска на doi обязательна

Международное право и международные организации•4•2016

International Law and International Organizations

3. Milberg W., Amengual M. Economic Development and Working Conditions in Export Processing Zones: A Survey of Trends / W. Milberg, M. Amengual. - Geneva, 2008 // International Labour Organisation: ofitsial'nyi sait. [Elektronnyi resurs]. - Rezhim dostupa: http://ilo.org/public/french/ dialogue/download/wp3englishfinal.pdf (data obrashcheniya - 07.08.2016), r. 62

4. Hemphill T.A., White G.O. III. The World Economic Forum and Nike: Emerging 'Shared Responsibility' and Institutional Control Models for Achieving a Socially Responsible Global Supply Chain? / T.A. Hemphill, G.O. White III // Business and Human Rights Journal. - 2016. - №1. - Rp. 307-313. doi:10.1017/bhj.2016.3

5. Paine L.S., Katz J.P. Levi Strauss \& Co.: Global Sourcing (A) / L.S. Paine, J.P. Katz // Harvard University Graduate School of Business Administration Case \#9-395-f, November 1994 (revised February 1997).

- Boston: Harvard Business School Press, pp.127-128.

6. Posner M.S. Disney and Other Big Brands Need to Address the Real Challenges to Outsourcing / M.S. Posner // The New York Times, (2 May 2013). [Elektronnyi resurs]. - Rezhim dostupa: http:// www.nytimes.com/roomfordebate/2013/05/02/when-does-corporate-responsibilitymean-abandoning-ship/disney-and-other-big-brands-need-to-address-the-real-challenges-to-outsourcing (data obrashcheniya - 07.08.2016)

7. Lyutov N.L. Perspektivy ratifikatsii Rossiei konventsii MOT / N.L. Lyutov // Trudovoe pravo. -2010. - №2(120). - S. 89-96. - S. 90

8. Cooper S. Improving Worker Safety in Global Supply Chains: The Case for a Global Safety \& Health Management System / S. Cooper // Professional Safety. - 2014. - October. - Rr. 29-33 